\title{
Study on Thrust Hydraulic System of TBM Based on AMESim \& MATLAB/Simulink Interface
}

\author{
Xiangdong $\mathrm{Gao}^{1, \mathrm{a}}$, Jianxi Yang ${ }^{1, \mathrm{~b}}$ and Kui Chen ${ }^{2, \mathrm{c}}$ \\ ${ }^{1}$ School of Mechanical \&Electrical Engineering, Henan University of Science\& Technology, Luoyang \\ 471003, China; \\ ${ }^{2}$ State Key Laboratory of Shield Machine and Boring Technology, China Railway Tunnel Group, \\ Zhengzhou 450001, China \\ a1393886280@qq.com, ${ }^{\mathrm{b}} \mathrm{yj} \times 221 @ 163 . c o m,{ }^{\mathrm{c}}$ chenkui-center@foxmail.com
}

Keywords: TBM, thrust hydraulic system, improved PID controller, GA.

\begin{abstract}
The choice of fuzzy rules and membership function of fuzzy self-adjusting PID controller of tunneling boring machine (TBM)'s thrust hydraulic system exists the defect of subjectivity to a great extent. The genetic algorithm (GA) was adopted to optimize fuzzy rules and parameters of membership function and an improved PID controller based on GA was designed. In order to conduct the co-simulation, the mechanical model was built in AMESim and control model was designed in MATLAB/Simulink and co-simulation interface was used to carry out the co-simulation. The simulation results show that the improved PID controller can eliminate the overshoot and improved the response and steady state performance.
\end{abstract}

\section{Introduction}

With the rapid development of social productivity, TBM is becoming more and more popular in long linear tunnel construction. As the heart of TBM, the thrust hydraulic system is not only to realize the movement forward of TBM's thrust cylinder, but also to achieve TBM's postural adjustment and fallback alone when the segment is installed [1].So far, according to the study on thrust hydraulic system of TBM, predecessors have already done a lot of interesting research work and achieved fruitful results. Yang et al [2] applied pressure and velocity compound control strategy based on fuzzy self-adjusting PID algorithm to accomplish speed-control of TBM's thrust hydraulic system. Liu et al [3] designed an adaptive PID controller for thrust speed of TBM's thrust hydraulic system based on BP neural networks. Shi et al [4] designed the PID controller based on the single neural to achieve the adaptive control of shield's thrust speed. Hou et al [5] used the algorithm of RBF neural network to control the speed of hydraulic thrust system of telescopic shield TBM. This paper applied GA to optimize the parameters of membership function and the rules of fuzzy PID controller. The simulation results show that the improved controller has eliminated the overshoot phenomenon and enhanced the robustness of hydraulic thrust system, which has made TBM's thrust system a good performance.

\section{Introduction of TBM's Thrust Hydraulic System}

The principle of TBM's thrust hydraulic system is shown in Fig.1. When the system is in normal working condition, two four-way electromagnetic reversing valve 1 is closed and hydraulic fluid enters the big cavity of thrust cylinder by the way of proportional flow control valve, the right of three four-way electromagnetic directional valve 1, hydraulic-lock 5 and balanced valve 6 to drive disc cutters to cut soil. When TBM is installing the segments, proportional flow control valve is shorted and the fluid enters the rod cavity by the way of two four-way directional valves 1 , the left of three four-way directional valve 4 and balanced valve 6 to accomplish the movement of rapid fallback. In this process, balanced valve 6 can ensure the stability of fallback operation. When the system is holding the pressure, for example, when the operation is to change tools, with hydraulic 
lock 5 and $\mathrm{Y}$ in a function of the three four-way directional valve 4, the system forms a locking-circuit and can avoid the leakage of fluid when the excavation is stop.

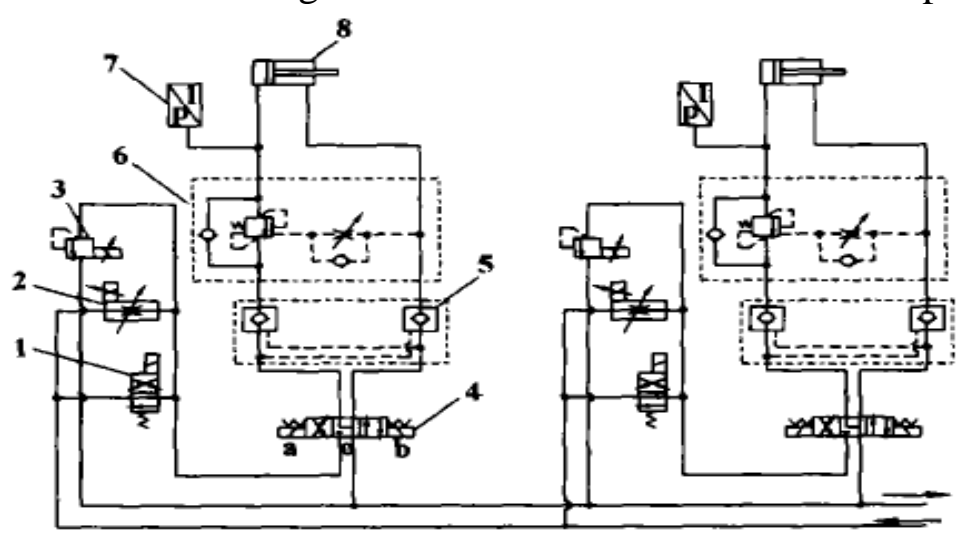

1.two four-way electromagnetic reversing valve 2.proportional flow control valve 3.proportional pressure relief valve 4.three four-way electromagnetic directional valve 5.hydraulic-lock 6.balanced valve 7.cylinder

Fig.1 The principle of thrust hydraulic system

\section{Optimum Design of Fuzzy Self-adjusting PID Controller Based on GA}

\section{The Design of Fuzzy Self-turning PID Controller.}

Inputs of fuzzy self-turning PID controller are error $\mathrm{E}$ and its change rate EC and $\mathrm{K}_{\mathrm{p}} 、 \mathrm{~K}_{\mathrm{i}}$ and $\mathrm{K}_{\mathrm{d}}$ are intermediate variables. Fuzzy outputs are the adjustment values of $\Delta \mathrm{K}_{\mathrm{p}}, \Delta \mathrm{K}_{\mathrm{i}}$ and $\Delta \mathrm{K}_{\mathrm{d}}$. The basic domain of inputs and outputs is [-3 3] and the fuzzy domain is $\{-3,-2,-1,0,1,2,3\}$. The adaptive parameters of every control cycle are calculated according to the following formula:

$$
\begin{aligned}
& \mathrm{K}_{\mathrm{d}}=\mathrm{K}_{\mathrm{d} 0}+\Delta \mathrm{K}_{\mathrm{d}} \\
& \mathrm{K}_{\mathrm{d}}=\mathrm{K}_{\mathrm{d} 0}+\Delta \mathrm{K}_{\mathrm{d}} \\
& \mathrm{K}_{\mathrm{d}}=\mathrm{K}_{\mathrm{d} 0}+\Delta \mathrm{K}_{\mathrm{d}}
\end{aligned}
$$

In above formulas, $\mathrm{K}_{\mathrm{p} 0} 、 \mathrm{~K}_{\mathrm{i} 0} 、 \mathrm{~K}_{\mathrm{d} 0}$ are initial values of fuzzy controller. The fuzzy subsets of error $E$, error change rate ES and fuzzy outputs $\Delta K_{p} 、 \Delta K_{i}$ and $\Delta K_{d}$ are \{NB NM NS ZO PS PM $\mathrm{PB}$ \}and they represent positive big, positive media, positive small, zero, negative small, negative media, negative big respectively. Fuzzy membership functions of $\mathrm{E} 、 \mathrm{EC}$ and $\Delta \mathrm{K}_{\mathrm{p}} 、 \Delta \mathrm{K}_{\mathrm{i}}$ and $\Delta \mathrm{K}_{\mathrm{d}}$ were all defined by the trigonometric function which takes up a small memory space and is high-resolution. According to the technological knowledge and practical experiences of engineers and technicians, the fuzzy control rules was built and the adjustment laws of $\Delta \mathrm{K}_{\mathrm{p}} 、 \Delta \mathrm{K}_{\mathrm{i}}$ and $\Delta \mathrm{K}_{\mathrm{d}}$ are shown in the table 1 . In the end, Mamdani method was adopted to carry out fuzzy inference and weighted average method (WAM) was used to remove fuzziness. 
Table.1 Fuzzy control rules of $\Delta \mathrm{K}_{\mathrm{p}}, \Delta \mathrm{K}_{\mathrm{i}}$ and $\Delta \mathrm{K}_{\mathrm{d}}$

\begin{tabular}{|c|c|c|c|c|c|c|c|}
\hline $\mathrm{Ec}$ & NB & NM & NS & $\mathrm{ZO}$ & PS & $\mathrm{PM}$ & PB \\
\hline NB & $\begin{array}{c}\mathrm{PB} / \mathrm{NB} / \\
\mathrm{PS}\end{array}$ & $\begin{array}{c}\mathrm{PB} / \mathrm{NB} / \\
\mathrm{NS}\end{array}$ & $\begin{array}{c}\mathrm{PM} / \mathrm{NM} / \\
\mathrm{NB}\end{array}$ & $\begin{array}{c}\mathrm{PM} / \mathrm{NM} / \\
\mathrm{NB}\end{array}$ & $\begin{array}{c}\text { PS/NS/ } \\
\text { NB }\end{array}$ & $\begin{array}{c}\mathrm{ZO} / \mathrm{ZO} / \\
\mathrm{NM}\end{array}$ & $\begin{array}{c}\mathrm{ZO} / \mathrm{ZO} / \\
\mathrm{PS}\end{array}$ \\
\hline NM & $\begin{array}{c}\mathrm{PB} / \mathrm{NB} / \\
\mathrm{PS}\end{array}$ & $\begin{array}{c}\mathrm{PB} / \mathrm{NB} / \\
\mathrm{NS}\end{array}$ & $\begin{array}{c}\mathrm{PM} / \mathrm{NM} / \\
\mathrm{NB}\end{array}$ & $\begin{array}{l}\mathrm{PS} / \mathrm{NS} / \\
\mathrm{NM}\end{array}$ & $\begin{array}{c}\text { PS/NS/ } \\
\text { NM }\end{array}$ & $\begin{array}{c}\mathrm{ZO} / \mathrm{ZO} / \\
\mathrm{NS}\end{array}$ & $\begin{array}{c}\mathrm{NS} / \mathrm{ZO} / \\
\mathrm{ZO}\end{array}$ \\
\hline NS & $\begin{array}{c}\mathrm{PM} / \mathrm{NB} / \\
\mathrm{ZO}\end{array}$ & $\begin{array}{c}\mathrm{PM} / \mathrm{NM} / \\
\mathrm{NS}\end{array}$ & $\begin{array}{c}\mathrm{PM} / \mathrm{NS} / \\
\mathrm{NM}\end{array}$ & $\begin{array}{l}\mathrm{PS} / \mathrm{NS} / \\
\mathrm{NM}\end{array}$ & $\begin{array}{c}\mathrm{ZO} / \mathrm{ZO} / \\
\mathrm{NS}\end{array}$ & $\begin{array}{c}\text { NS/PS/ } \\
\text { NS }\end{array}$ & $\begin{array}{c}\text { NS/PS/ } \\
\text { ZO }\end{array}$ \\
\hline $\mathrm{ZO}$ & $\begin{array}{c}\mathrm{PM} / \mathrm{NM} / \\
\mathrm{ZO}\end{array}$ & $\begin{array}{c}\mathrm{PM} / \mathrm{NM} / \\
\mathrm{NS}\end{array}$ & $\begin{array}{c}\text { PS/NS/ } \\
\text { NS }\end{array}$ & $\begin{array}{c}\mathrm{ZO} / \mathrm{ZO} / \\
\mathrm{NS}\end{array}$ & $\begin{array}{c}\text { NS/PS/ } \\
\text { NS }\end{array}$ & $\begin{array}{c}\mathrm{NM} / \mathrm{PM} / \\
\mathrm{NS}\end{array}$ & $\begin{array}{c}\mathrm{NM} / \mathrm{PM} / \\
\mathrm{ZO}\end{array}$ \\
\hline PS & $\begin{array}{c}\text { PS/NM/ } \\
\text { ZO }\end{array}$ & $\begin{array}{l}\text { PS/NS/ } \\
\text { ZO }\end{array}$ & $\begin{array}{c}\mathrm{ZO} / \mathrm{ZO} / \\
\mathrm{ZO}\end{array}$ & $\begin{array}{c}\text { NS/PS/ } \\
\text { ZO }\end{array}$ & $\begin{array}{c}\text { NS/PS/ } \\
\text { ZO }\end{array}$ & $\begin{array}{c}\text { NM/PM/ } \\
\mathrm{ZO}\end{array}$ & $\begin{array}{c}\mathrm{NM} / \mathrm{PB} / \\
\mathrm{PB}\end{array}$ \\
\hline $\mathrm{PM}$ & $\begin{array}{l}\mathrm{PS} / \mathrm{ZO} / \\
\mathrm{PB}\end{array}$ & $\begin{array}{c}\mathrm{ZO} / \mathrm{ZO} / \\
\mathrm{NS}\end{array}$ & $\begin{array}{c}\text { NS/PS/ } \\
\text { PS }\end{array}$ & $\begin{array}{c}\text { NM/PS/ } \\
\text { PS }\end{array}$ & $\begin{array}{c}\text { NM/PM/ } \\
\text { PS }\end{array}$ & $\begin{array}{c}\text { NM/PB/ } \\
\text { PS }\end{array}$ & $\begin{array}{c}\text { NB/PB/ } \\
\text { PB }\end{array}$ \\
\hline PB & $\begin{array}{c}\mathrm{ZO} / \mathrm{ZO} / \\
\mathrm{PB}\end{array}$ & $\begin{array}{c}\mathrm{ZO} / \mathrm{ZO} / \\
\mathrm{PM}\end{array}$ & $\begin{array}{c}\text { NM/PS/ } \\
\text { PM }\end{array}$ & $\begin{array}{c}\text { NM/PM/ } \\
\text { PM }\end{array}$ & $\begin{array}{c}\text { NM/PM/ } \\
\text { PS }\end{array}$ & $\begin{array}{c}\text { NB/PB/ } \\
\text { PS }\end{array}$ & $\begin{array}{c}\text { NB/NB/ } \\
\mathrm{PB} \\
\end{array}$ \\
\hline
\end{tabular}

\section{Optimization of Fuzzy PID Controller Based on GA.}

GA is consist of duplication, crossover and mutation operator and is a random search algorithm. Due to GA don't limit the questions to the specific field and have a good robustness for different questions, on the other hand, it is able to search many dots of the solving-space at a time and seek adequately and make them rapid global convergence, it is the general framework of solving complex system optimization [6]. The flow chart of GA is shown in Fig2. The control system based on GA is made up of two sections, which is basic fuzzy controller and GA improved unit. Basic fuzzy controller controls the controlled objects and GA improved unit adjusts and optimizes the basic fuzzy controller. The structure of the system is shown in Fig3.

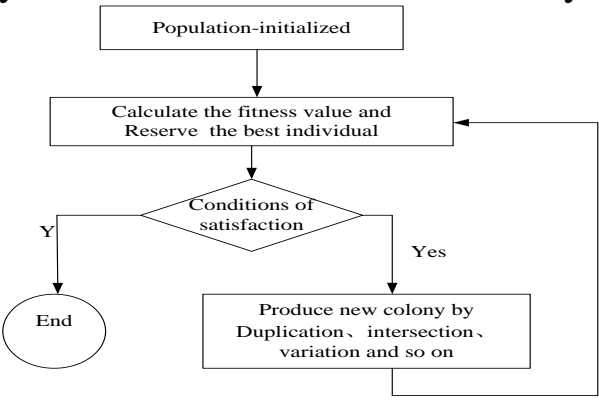

Fig.2 Flow chart of GA

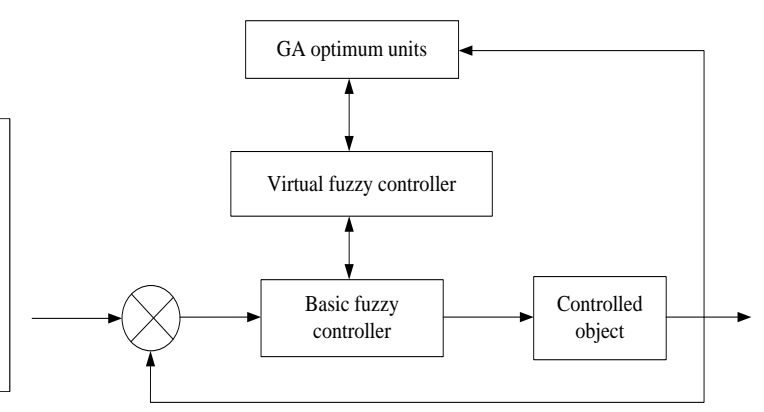

Fig.3 Structure of the control system based

\section{1) Optimization of Fuzzy Membership Functions Based on GA}

The membership function is usually modified gradually through experiments and it is difficult to get the best one. The common form of fuzzy membership functions are triangular, normal and trapezoid and so on. This article adopted triangular and its fuzzy membership function showed as:

$$
f_{\mathrm{A} 1}(x)=\left\{\begin{array}{l}
1-\left(\frac{b_{i}-x}{a_{i}}\right) x \leq b_{i}, a_{i}>0 \\
1-\left(\frac{b_{i}-x}{c_{i}}\right) x>b_{i}, c_{i}>0
\end{array}\right.
$$

$\left(\mathrm{a}_{i}, b_{i}, c_{i}\right)$ are the parameters of membership function. For $\mathrm{N}$-dimension inputs $\left(\mathrm{x}_{1}, x_{2}, \ldots . x_{n}\right)$,the membership of its fuzzy outputs based on the i-st rule in the set of rules is:

$$
\begin{aligned}
& \left\{\begin{array}{l}
1-\left(\frac{b_{i}-x}{a_{i}}\right) \\
1-\left(\frac{b_{i}-x}{c_{i}}\right)
\end{array}\right. \\
& f_{B}^{i}=\min \left\{f_{A 1}^{i}\left(x_{1}, a_{1}^{i}, b_{1}^{i}, c_{1}^{i}\right) \ldots f_{A n}^{i}\left(x_{n}, a_{n}^{i}, b_{n}^{i}, c_{n}^{i}\right)\right\}
\end{aligned}
$$


The membership is a function of $\left(\mathrm{a}_{j}^{i}, b_{j}^{i}, c_{j}^{i}\right), \mathrm{j}=1,2,3 \ldots n$ and the fuzzy membership of the whole outputs is also a function of $\left(\mathrm{a}_{j}^{i}, b_{j}^{i}, c_{j}^{i}\right)$. The ambiguity is max-min fuzzy inference method and the centre of gravity method.

It can be seen that $\mathrm{f}$ is defined by the parameters $\left(\mathrm{a}_{i}, b_{i}, c_{i}\right)$ of membership functions and inputs $\left(x_{1}, x_{2}, \ldots x_{n}\right)$. When the number of inputs' variables is certain, if the parameters $\left(\mathrm{a}_{i}, b_{i}, c_{i}\right)$ were chosen rationally, it can minimize the formula

$$
J=\sum_{i=1}^{n}\left(y_{i}-y_{i}^{0}\right)^{2}
$$

$\mathrm{y}_{i}$ is the real output and $\mathrm{y}_{i}^{0}$ is the desired output. Therefore, a fuzzy system involved several variables and every variable contained several subsets and the fuzzy membership function of every subset included n parameters. In this way, the parameters' optimization of the whole membership functions can be transformed into the multi-dimension parameters' optimizing operation corresponding to the constraint conditions (2) and (3) when the formula(4) is minimum and GA provides a effective way to solve this problem.

\section{2) Optimization of Fuzzy Control Rules Based on GA}

The most important question of optimization of fuzzy control rules based on GA is how to code the rules well. This paper chooses the string of binary encode to code and there are 49 rules to be optimized. Every rule is shown in four binary that one stands for the control-bit and others do the rule-bit and then they are concatenated into a chromosome, which is the most general "series binary code" method. In this way, former fuzzy language values $\{\mathrm{NB}, \mathrm{NM}, \mathrm{NS}, \mathrm{ZO}, \mathrm{PS}, \mathrm{PM}, \mathrm{PB}\}$ can be expressed in three binary respectively and the fuzzy rules was coded into $\{000,001,010,011,100,101,110)$. So the rule chromosomes are made of 49 bit control genes and $3 \times 49$ bit rule genes and can realize the single-level control to rule genes through control genes. Individual fitness function can be expressed:

$$
F=-\int_{0}^{\mathrm{t}} t|e| d t
$$

The optimization of the objective function is very good when it was used to the control system. The running parameters contained: group size $\mathrm{M}$, genetic generations, crossover probability $\mathrm{P}_{\mathrm{m}}$ and mutation probability $\mathrm{P}_{\mathrm{c}}$ and so on.

\section{Modeling and Simulation of TBM's Thrust Hydraulic System}

\section{Modeling of Mechanical System.}

Firstly, selected corresponding components depended on the specification of parts of thrust hydraulic system and built the models in the AMESim of electromagnetic proportional flow control valve and pressure relief valve and then optimized concerned parameters of every component with the batch process function of AMESim to meet the performance indicators. The simulation model of TBM's thrust hydraulic system is shown in Fig.5. In the process of modeling, only considered the dynamic relationship of proportional flow control valve, pressure relief valve, hydraulic cylinder and hydraulic load and left out these components which had a slightly influence on system performance. In this way, the thrust hydraulic system was simplified properly and used a constant voltage source to conduct this simulation finally. 


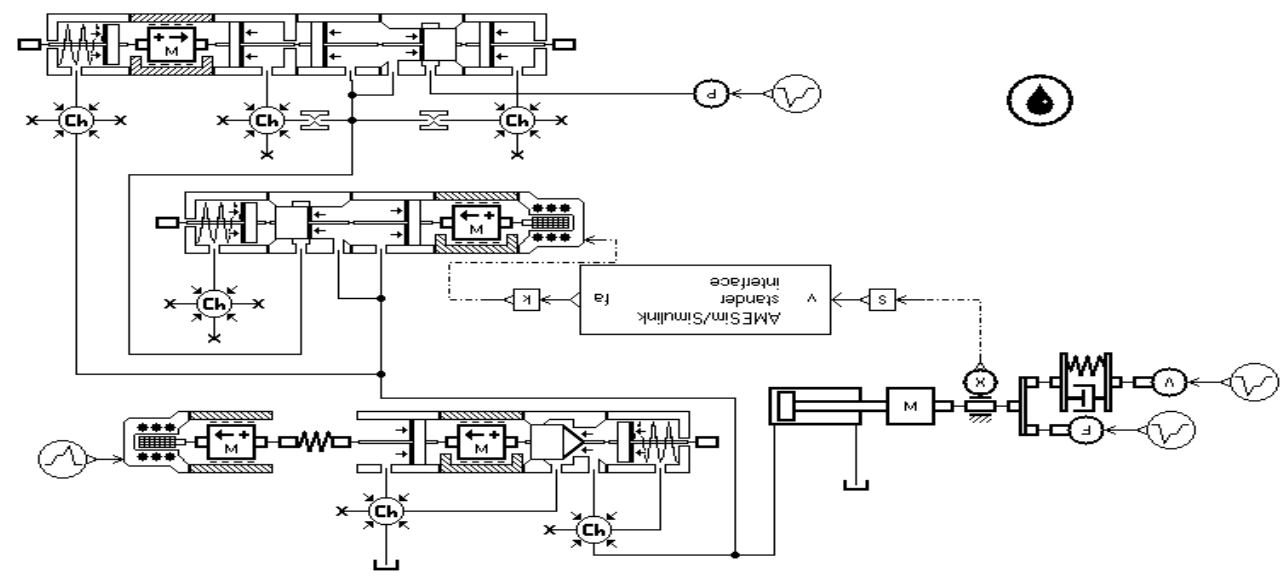

Fig.4 Mechanical model of TBM’s thrust hydraulic system

\section{Modeling of Control System.}

On the basis of the optimization model based on GA above, write s-function program of the control algorithm in MATLAB and put up the simulation model of the control system in MATLAB/Simulink. The simulation model is shown in Fig.5.

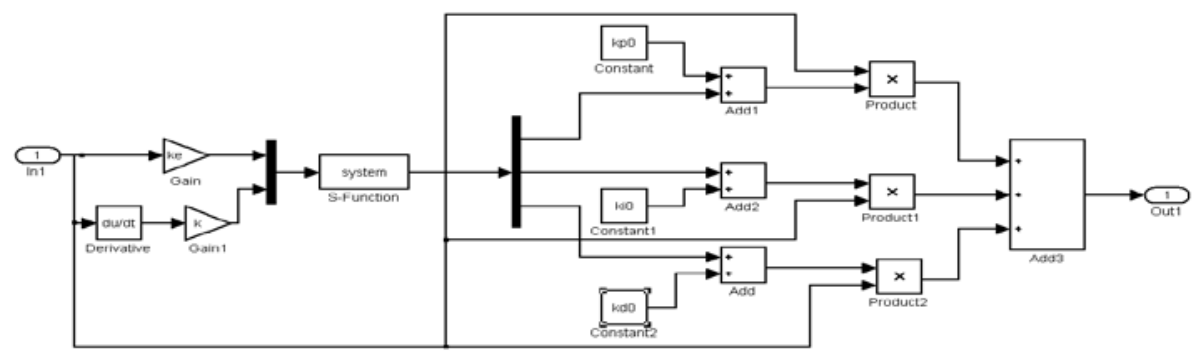

Fig.5 Simulation model of control system based on GA

\section{Co-simulation Analysis Based on AMESim and MATLAB/Simulink Interface.}

Import the model which is built in AMESim to MATLAB/Simulink and create the co-simulation model in MATLAB/Simulink .The controller (Fig.4) is the fuzzy PID controller which has been optimized based on GA and the controlled object is the AMESim model of thrust hydraulic system. AMESim provides two kinds of interfaces which is the standard interface and the co-simulation interface and the simulation adopted the latter. In the co-simulation, every software used each solver to carry out simulation and AMESim model is regard as time-discrete module in MATLAB which can match with the control module better. In the simulation, the initial PID parameters set as $K_{p 0}=0.5, K_{i 0}=0.1, K_{d 0}=0.1$, load force sets as $1000 \mathrm{KN}$, system pressure setting is 23MPa and the simulation time is $10 \mathrm{~s}$ in which the thrust speed is $0.5 \mathrm{~mm} / \mathrm{s}$ in the first five seconds and the second five seconds is $1 \mathrm{~mm} / \mathrm{s}$. GA parameters setting are $\mathrm{M}=60, \mathrm{~T}=100, \mathrm{P}_{\mathrm{m}}=0.008$ and $\mathrm{P}_{\mathrm{c}}=1$. The co-simulation model was shown in Fig.6.

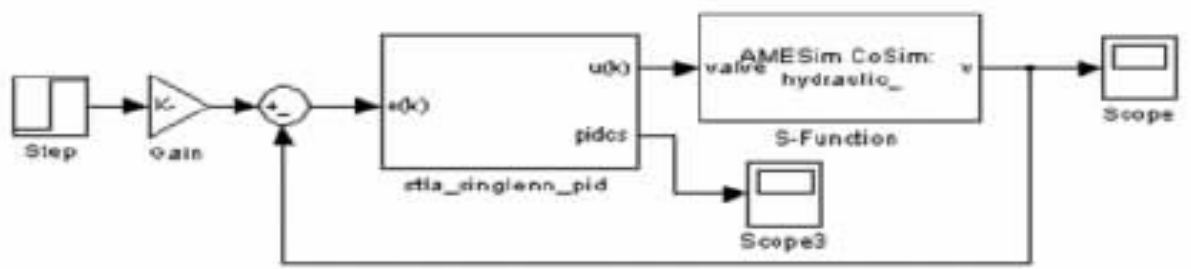

Fig.6 Co-simulation model of TBM’s thrust hydraulic system

The speed curve of TBM's hydraulic thrust system based on fuzzy adaptive PID controller is shown in Fig.a and the Fig.b is the curve based on optimum fuzzy PID controller baesd on GA. It can be seen from these simulation results that after the membership functions and the control rules of fuzzy self-turning PID controller was optimized by GA, the adjustment time of TBM's thrust speed became short and the overshoot phenomenon is eliminated,at the same time its robustness and adaptive capacity was improved. The simulation results show that optimum PID controller succeed 
in controlling of TBM's thrust hydraulic system and achieving a good tracking performance.
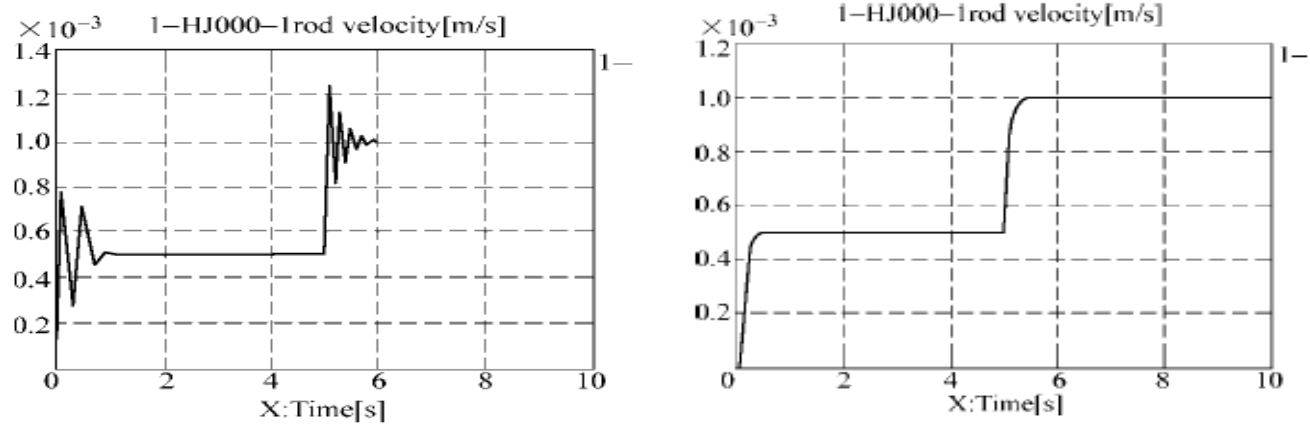
a) Fuzzy adaptive PID control
b) Fuzzy PID optimization control based on GA

Fig.7 Co-simulation analysis

\section{Summary}

(1) Apply GA to optimize fuzzy membership and control rules of TBM's thrust hydraulic system. The co-simulation study is done based on AMESim and Simulink interface in the paper.

(2) Compared to the simulation results of the fuzzy-adaptive PID controller, we can seen that after TBM's thrust hydraulic system adapted the improved controller which is optimized by GA, the overshoot phenomenon is eliminated and the dynamic response becomes rapid at the same time. We can draw a conclusion that the improved controller has not only static and dynamic performance, but also high robustness and adaptive ability.

\section{References}

[1] Deng Yingcong, Guo Weizhong, Gao Feng. Equivalent Mechanism-based Modeling for Grouping Performance Analysis of the Thrust System of Shield Machines. Journal of Mechanical Engineering.Vol.46(2010) NO.13,p.122-126.

[2] Yang Yang, Gong Guofang, Hu Guoliang, et al. Simulation of Shield's Thrust Hydraulic System Based on AMESim and MATLAB. Machine Tool \& Hydraulics. Vol.34(2006) NO.6,p.119-121.

[3] Liu Guobin, Gong Guofang, Zhu Beidou, et al. Adaptive PID Control for Thrust Speed of the Shield Based on BP Neural Networks. Journal of Engineering Design. Vol.17(2010) NO.6,p.454-458.

[4] Shi Hu, Gong Guofang, Yang Huayong, et al. Adaptive PID Control for Thrust Speed of Shield Based on Single Neuron. China Mechanical Engineering. Vol.20(2009) NO.2,p.138-141.

[5] Hou Kunzhou, Xu Liping, Ren Dezhi, et al. Speed Control for Hydraulic Thrust System of Telescopic Shield Tunneling Machine Based on RBF-NN Self-turning PID Controller. Hydraulics Pneumatics \& Seals. (2010)NO.3,P.19-23.

[6] Zhou Ming, Sun Shudong. GA Principle \& Applications. The Aromatic Industry Press, 1999,p. 221-245. 